\title{
Willingness to Pay to Avoid Water Restrictions in Australia Under a Changing Climate
}

\author{
Bethany Cooper $^{1} \cdot$ Michael Burton ${ }^{2,3}$ (D) \\ Lin Crase $^{1}$ (D)
}

Accepted: 29 January 2018 / Published online: 2 March 2018

(C) The Author(s) 2018. This article is an open access publication

\begin{abstract}
Mandatory water use restrictions have become a common feature of the urban water management landscape in countries like Australia. Water restrictions limit how water can be used and their impacts have often been enumerated by using stated preference techniques, like contingent valuation. Most interest in these studies emerged in times of drought, when the severity of restrictions and their deployment had increased and water managers contemplate supply augmentation measures. A question thus arises as to whether the same estimates can be legitimately deployed to water supply projects undertaken when water is more plentiful. This study sheds light on the impact on estimates of willingness to pay when the climatic backdrop to a contingent valuation experiment is altered. We report the results of a comparison between two surveys, undertaken in 2008 and 2012, using a common multiple-bounded discrete choice contingent valuation design, administered across six cities in Australia, covering metropolitan and regional settings. Using a finite mixture, scaled ordered probit model we investigate changes over time in willingness to pay by city, and also causes of individual heterogeneity in willingness to pay. We find that willingness to pay estimates significantly change over time in most regional centres but this is not the case for the major cities of Sydney and Melbourne, once changes in housing prices are included in the analysis.
\end{abstract}

Keywords Contingent valuation · Urban water restrictions · Framing effects

Bethany Cooper

bethany.cooper@unisa.edu.au

1 School of Commerce, Business School, University of South Australia, GPO Box 2471, Adelaide, SA 5001, Australia

2 School of Social Sciences, University of Manchester, Manchester, UK

3 School of Agriculture and Environment, University of Western Australia, 35 Stirling Highway, Crawley Western Australia 6009, Australia 


\section{Introduction}

The climate variability that characterises Australia makes periods of drought the norm. The unprecedented 'millennium drought' in south-eastern Australia between the late 1990s and the first decade of the 2000s triggered several policy responses, including conservation measures and 'demand management' initiatives that prohibit some water uses. Historically, these constraints have been limited to outdoor activities, or what is considered 'discretionary' water use (National Water Commissions 2007), but the notion of mandatory restrictions on household water use is now well-engrained in planning and policy in major urban centres.

Considerable debate in the literature surrounds the value of regulation or market driven approaches to water conservation (Allon and Sofoulis 2006; Grafton and Ward 2008; Pumphrey et al. 2008). Much of the argument lies on the negative aspects of enforcing water restrictions and other conservation measures over a sustained and long term (Willis et al. 2013). Water restrictions usually constrain the time at which outdoor water can be used and/or the particular uses of water. For instance, households are often assigned specific days that they are permitted to undertake water-using activities, such as watering gardens but not lawns, late in the evening and only with a bucket or hand-held hose.

In contrast to this regulatory approach, Barrett (2004) observes that there is a worldwide trend to use the market as a strategy for reducing consumption on a range of essential services. Essentially, the market approach suggests that increasing prices and moving full cost recovery on to the consumer is the most efficient conservation mechanism, as the price is the main motivator for consumption reduction. Public opposition to raising water prices makes the price increase strategy challenging (OECD 2000), and often information on the real costs are not available (Barrett 2004). Other questions emerge about the capacity of price increases alone to rein in demand, and clearly supply augmentation works that are not rainfall-dependent are also an option, such as desalination plants. However, to rationalise such expensive and long-lived projects it is necessary to understand the benefits to users who can avoid water restrictions over a longer term.

Whilst a variety of approaches are available to inform water planners about demand (see, for example, Castledine et al. 2014) stated preference techniques, such as discrete choice modelling and contingent valuation (CV) are also helpful (see, for instance, Hensher et al. 2006; Cooper et al. 2011; Brennan et al. 2007; Syme et al. 2004). This is especially the case when options for meeting demand and the related benefits are unknown ex ante.

Water infrastructure is also generally long-lived and involves lumpy investment choices at a point of time. This raises the question as to whether it is appropriate to use the welfare values generated from stated preference studies at a particular point in time (e.g. drought) in the water planning process as the basis for rationalising expenditures on costly and slowto-build infrastructure. For example, in response to drought many Australian governments constructed desalination plants but several subsequent years of high rainfall raises questions about the impact of context on the results generated by stated preference experiments that were previously deployed at a time of drought and partly used to justify projects. It might not be surprising that studies focused on the mechanisms of dealing with drought are common in Australia, but given the global interest in increased rainfall variability and water scarcity these results potentially provide lessons elsewhere.

Recent reviews of stated preference techniques identify concern about the impact of "framing" (Howard and Salkeld 2009). In the interest of clarity we distinguish "framing" which relates to elements of the survey (e.g. nomenclature, elicitation method) from "context" which creates the backdrop to the experiment, and which is not explicitly determined by the 
researcher. For instance, we consider the climatic conditions at the time of data collection as a context in which the experiment is conducted, and which may significantly influence the results. Framing effects are well recognised in the literature (Tversky 1996; Starmer 2000). More specifically, there is evidence that minor alterations in the framing of scenarios can have a material impact upon the choices made. Kahneman and Tversky (1979) suggest that changing the presentation of probabilities and outcomes can encourage changes in individuals' interpretation of information and consequent decision-making behaviour. Moreover, their famous "Asian disease" study found that changing the labelling of outcomes (the more attractive alternative was dependent on whether outcomes were framed as lives saved, or lives lost) results in material differences. Framing effects of a similar nature have been established in other areas such as public policy, taxation, health, political preferences, contract negotiations, and environmental policy (Howard and Salkeld 2009; Frederickson and Waller 2005; Ovaskainen and Kniivila 2005; Rege and Telle 2004; Miller 2000).

This study departs from the existing literature by exploring the effect of contextual factors on willingness to pay (WTP) from a CV experiment. More specifically, we investigate if there is a significant change in WTP to avoid water restrictions when studies are administered against distinctly different climate backgrounds; namely during a prolonged drought and then 4 years later following a succession of wetter years. Part of the motivation for this study is that, under most long-run marginal cost regulatory approaches to water pricing, choices made in one context (e.g. drought) flow through to prices that must be accommodated in another setting (e.g. non-drought) and factoring these impacts into the information available to policy makers could be influential. Similarly, there are challenges with benefit transfer in this context. Benefit transfer implies taking the values from one stated preference experiment and applying them elsewhere. There is ample literature on the usefulness and limits of this approach (see, e.g. Johnston et al. 2015), and context is manifestly an important consideration. There is a particular issue with inter-temporal benefit transfer, where values are expected to hold constant over what may be considerable periods of time. There is some evidence that suggests that there is a degree of intertemporal consistency (e.g. Burton and Rigby 2016), but often test-retest studies are interested in consistency of the choice process (e.g. Brouwer 2012) rather than how changing temporal context may manifest itself in changing preferences. The case of drought versus non-drought is an interesting issue to explore this, as the changing context may involve high levels of media salience. The study uses data from respondents living in metropolitan and regional centres and also aims to identify the significant drivers of individuals' WTP.

As noted, our primary interest is whether the altered climatic background modifies earlier estimates of willingness to pay. However, questions also arise about the motivations that might bring those changes about. Stated preference techniques are increasingly adopted to assist with analysis into the drivers of choice and significant developments in the choice modelling and CV techniques have been made to achieve this goal (see, e.g. Hensher et al. 2005). With this in mind, this study seeks to make a significant contribution to the existing literature on a number of grounds. First, a comparison model is estimated using WTP data from Cooper et al. (2011) collected in 2008 during drought (referred to as Sample 1) and the data from the current study, collected in 2012, post drought (referred to as Sample 2). Thus, the study not only provides insight into variations in preferences across cities but also over time and against a changing climatic backdrop. Second, we analyse the more recent data (Sample 2) to determine if there are some segments of the population that lose welfare from avoiding water restrictions, and are thus not prepared to pay any amount to avoid restrictions. Third, we use two approaches to deal with the matter of certainty of respondents' preference over water restrictions, including explicit identification through the 
question format of the certainty with which they make their choice, and an investigation of error variance.

The four main objectives of this paper are to: (1) identify if there is a significant difference in the WTP estimates between the CV data reported in Cooper et al. (2011) in 2008 (Sample 1) and the CV data collected for this study in 2012 (Sample 2); (2) identify what demographic and psychographic variables significantly influence respondents' WTP to avoid water restrictions; (3) identify the portion of respondents who do not demonstrate any response to the bids and the variables that are significant to this class; (4) identify what variables significantly influence the predictability of an individual's WTP to avoid water restrictions.

The paper itself is divided into six parts. Section 2 provides a synopsis of the existing literature that uses stated preference techniques to evaluate the impacts of water restrictions. In Sect. 3, the design and sampling for this study are discussed before we briefly consider the theoretical grounding of the $\mathrm{CV}$ model employed. The statistical model employed (the finite mixture, scaled ordered probit model used in Cooper et al. (2011)) is outlined in Sect. 4. Two applications of the model are reported: a comparison model that pools data from 2008 and 2012, which allows us to identify contextual effects. Subsequently, a more extensive model is estimated using the 2012 data to investigate the heterogeneity associated with WTP to avoid water restrictions. The final section discusses the key findings and includes brief concluding remarks.

\section{Preferences Towards Water Restrictions}

A number of studies have investigated individuals' and households' preferences for drought water restrictions by employing the stated preference techniques of choice experiments and CV (Cooper et al. 2011; Hensher et al. 2006; Gordon et al. 2001; Koss and Khawaja 2001; Griffin and Mjelde 2000; Howe and Smith 1994). Most of these studies have occurred at a time of water scarcity. Estimates of the welfare losses vary, in part because the scenarios in the stated preference experiments differ. For example, the study by Hensher et al. (2006) was set in Canberra and a scenario of continuous water restrictions relate to a situation with no restrictions was offered, resulting in a WTP of about \$A240/year. Gordon et al. (2001) also conduct a choice experiment in Canberra, Australia that investigates preferences towards water restrictions. Their study suggests that households are willing to pay an extra \$150/year (in 1997 Australian dollars) for a more "voluntary" demand management approach as opposed to mandatory restrictions.

Howe and Smith (1994) use CV to estimate the value of water supply reliability in the United States. Their findings suggest that households would accept between $\$ 4.53$ and $\$ 13.99 /$ month (in 1994 US dollars), on average, for a decrease in supply security. Griffin and Mjelde (2000) and Koss and Khawaja 2001 also use CV, however these studies investigate customers' WTP to avoid water restrictions in the United States. In Griffin and Mjelde (2000) study, participants are willing to pay, on average, between $\$ 25.34$ and $\$ 34.39 /$ month (in 1997 US dollars) to avoid an incident of water restrictions. Koss and Khawaja (2001) found that respondents are willing to pay, on average, between \$11.67 and \$16.92/month (in 1993 US dollars) to avoid water restrictions. Notwithstanding the divergence in the WTP values across these studies, it is apparent that the estimated welfare gains from avoiding water restrictions are non-trivial and could potentially influence the findings of benefit/cost analysis of supply augmentation projects.

Cooper et al. (2011) study departs from these earlier experiments by offering some insight into the heterogeneity of the urban water market. Again, this is an Australian study that uses 
CV to investigate WTP to avoid water restrictions. More specifically, a multiple-bounded discrete choice response format is used and the sample drawn from six cities in the states of Victoria and New South Wales. This study was conducted in 2008 following a decade of above average temperatures across Australia. Most cities had water restrictions in place from early to mid-2000 and for the duration of the study. Notably, Cooper et al. (2011) not only provide estimates of the welfare gain associated with avoiding water restrictions, but also drew on social and psychological models to provide insight into the influence of cognitive and exogenous dimensions on the utility associated with avoiding water restrictions.

In Cooper et al. (2011), the sample was drawn from 6 Australian cities that provided scope for a number of useful comparisons. For instance, the legislation and regulations pertaining to water restrictions differed, as did the severity with which they had been applied. There are specifics worth noting in this regard. Firstly, during the period of the millennium drought there was extensive political pressure directed at households, particularly in metropolitan cities, to adopt and comply with urban water restrictions. It was common for politicians and the media to portray restrictions as a moral duty and to appeal to metropolitan residents to 'share the burden' of rural districts and irrigation communities by restricting their water usage (Cooper et al. 2012). Extensive investment in media campaigns, accompanied this approach. Accordingly, the social stigma associated with not complying with water restrictions in the metropolitan cities, particularly Melbourne, became prominent, with numerous instances of social punishment, such as threats, vandalism and violence, occurring if individuals failed to comply with water restrictions (Australian Broadcasting Corporation 2008). Formal enforcement was also prominent in the major cities taking the form of water inspectors patrolling residential areas with the capacity to issue fines for non-compliance (Cooper et al. 2012). This was particularly the case in NSW and Sydney in particular. In contrast, the social and moral pressure to modify water use significantly eased post drought (after 2010).

Secondly, the differing proximities of the sample cities to water storages also provide scope for comparison. The cities of Albury and Wodonga are located adjacent to water storages so changes in supply levels are obvious to residents. Alternatively, residents in cities such as Melbourne and Sydney must rely on secondary sources of information to monitor changes on this front. Albury and Wodonga also generally had better water availability than other regional cities, such as Goulburn.

Another element to note is that water restrictions and their definition vary slightly by jurisdiction and the timing at which restrictions are applied and lifted is not uniform.

Notably, the definitions of each of the 'levels' of water restrictions and the degree of enforcement vary across the states and regions. In Victoria, the water restrictions levels for households range from 1-4, with level 4 being the most severe where all outside watering is banned. In Sydney, the water restriction levels range from 1-3. In this case, level 3 is the most severe and bans most outdoor water use, but still allows hand-held hose watering 1 day per week. In regional NSW, the water restrictions levels range from 1-5, where level 5 imposes a restriction on all outdoor water use.

Those cities that had lower availability to water sources (i.e. Goulburn and Bendigo) were more exposed to the drought because of the limited water supply options and the closer link between amenity and water availability.

Table 1 provides an outline of the of water restrictions that each of the residents in the sample cities faced leading up to and during the data collection periods.

The motivation of this study was to repeat the survey undertaken in 2008 , but after the drought had broken and cities had generally relaxed their more punitive water restrictions, to see if the estimated WTP to avoid restrictions changed. 
Table 1 Evolution of water restrictions for the 6 cities

\begin{tabular}{|c|c|c|}
\hline City & State & Water restrictions \\
\hline Melbourne & Victoria* & $\begin{array}{l}\text { Level } 1 \text { water restrictions from August } 2006 \\
\text { Level } 2 \text { water restrictions from November } 2006 \\
\text { Level } 3 \text { water restrictions from January } 2007 \\
\text { Level } 3 \text { a water restrictions from April } 2007 \\
\text { Level } 3 \text { water restrictions from April } 2010 \\
\text { Level } 2 \text { water restrictions from September } 2010 \\
\text { Level } 1 \text { water restrictions from December } 2011 \\
\text { Level } 2 \text { water restriction relaxed on December } 2012 \text { to permanent } \\
\text { water use rules }\end{array}$ \\
\hline Wodonga & Victoria* & $\begin{array}{l}\text { Level } 4 \text { water restrictions from July } 2007 \\
\text { Level } 3 \text { water restrictions from January } 2008 \\
\text { Water restrictions relaxed to permanent water saving rules in } 2010\end{array}$ \\
\hline Bendigo & Victoria* & $\begin{array}{l}\text { Level } 4 \text { water restrictions introduced in November } 2006 \\
\text { Water restrictions relaxed January } 2011 \text { to permanent water saving } \\
\text { rules } \\
\text { Major floods during } 2011 \text { were the largest on record for the region }\end{array}$ \\
\hline Goulburn & $\mathrm{NSW}^{\wedge}$ & $\begin{array}{l}\text { Level } 5 \text { water restrictions imposed from October } 2004 \\
\text { Won a National Water Conservation Award for Excellence due to } \\
\text { the water which had been conserved in } 2006 \\
\text { Level } 5 \text { water restrictions relaxed in } 2010 \text { to Level } 3\end{array}$ \\
\hline Albury & $\mathrm{NSW}^{\wedge}$ & $\begin{array}{l}\text { Level } 4 \text { water restrictions from July } 2007 \\
\text { Level } 3 \text { water restrictions from January } 2008 \\
\text { Level } 2 \text { water restrictions from January } 2009 \\
\text { Level } 4 \text { water restrictions from July } 2009 \\
\text { Level } 4 \text { water restrictions relaxed from May } 2010\end{array}$ \\
\hline Sydney & $\mathrm{NSW}^{\wedge}$ & $\begin{array}{l}\text { Level } 2 \text { water restrictions were introduced from June } 2004 \\
\text { Level } 3 \text { water restrictions from June } 2005 \\
\text { Level } 3 \text { water restrictions relaxed in June } 2009 \text { to Water Wise Rules }\end{array}$ \\
\hline
\end{tabular}

*Level 1-mild, Level 2-medium, Level 3-high, Level 3a-approaching critical, Level 4-critical

${ }^{\wedge}$ Level 1-mild, Level 2-medium, Level 3-high, Level 4-approaching critical, Level 5-critical

\section{Avoiding Water Restrictions Using CV: Post Drought Data Collection}

This study is not only focused on deriving WTP estimates, but also on drawing a comparison between $\mathrm{CV}$ data collected at two different points in time using the same response format; the first study (Sample 1) was conducted during a prolonged drought and the second study (Sample 2) conducted post drought.

This natural experiment comes with a number of limitations: in particular one cannot control for all other factors that may have changed over the period, independent of the break in drought. We attempt to control for as many other factors as possible in the analysis of the data (including individual and regional factors), but it should be acknowledged that any effects that we observe may be attributable to factors other than drought. In addition, we use city and year- fixed -effects to account for unobserved confounds. In both of these studies the focus is on preference for avoiding restrictions entirely (i.e. not in marginal changes 
in restriction regimes). Of particular interest is the certainty with which respondents hold such preferences. What follows is an explanation of the $\mathrm{CV}$ design and data collection for Sample 2. A description of the administration of Sample 1 is available in Cooper et al. (2011), although some elements of the design are common and summarised here for convenience.

\subsection{Design}

CV studies usually focus on valuing a good as a whole and in the current context this is useful for contemplating the WTP to avoid water restrictions in general. Different CV response formats are on offer including the dichotomous choice and multiple-bounded discrete choice (MBDC) response format (Cooper et al. 2011; Alberini et al. 2003; Cameron et al. 2002; Vossler et al. 2003). Cooper11, notes that part of the appeal of the MBDC is that the number of responses to bid levels is increased, which increases the efficiency of the welfare estimate (Rowe et al. 1996; Cooper et al. 2011).

The complete design is reported in Cooper et al. (2011) and there are two salient features to note.

First, this study used a payment card (MBDC) with an exponential response scale based on 13 bid levels. Initial estimation of bid levels employed Eq. 1 where the bid level, $B_{n}$, is associated with cells 1-12:

$$
B_{n}=1[1+k]^{n-1}, \quad n=1, \ldots, 12 .
$$

The value of $K[0.86]$ was selected so that $[1+k]^{11}$ produces a maximum value for the payment card that approximates the desired maximum value. In this case the desired upper bound was based on earlier WTP studies to avoid water restrictions (see Cooper et al. 2011) and gave rise to a value of $\$ 921$ per year (i.e., $(1.86)^{11}=921$ ). Since the value equals the percent increase between adjacent cells before smoothing and cell 13 contains the text "More than the above", application of Eq. (1) results in a nonlinear distribution of bids, with higher concentration at lower levels. To simplify matters for respondents bid amounts were rounded to the nearest ' 0 ' or ' 5 ' with the initial bid level of $\$ 1$ rounded down to $\$ 0$. It is worth noting that this rounding process has been shown to have no major impact on WTP outcomes (Rowe et al. 1996). The CV question and the final bid design appear in "Appendix A".

Second, the MBDC format used in this experiment required respondents to go beyond indicating their WTP at each level and to express a degree of certainty of payment. More specifically, respondents were asked to select from "definitely no", "probably no", "not sure," "probably yes," and "definitely yes" against each of the bid amounts.

This approach increases the amount of information obtained from each participant on their preferences over a range of bids and also about the certainty with which they hold that preference. Past research into the existence of anchoring and additional effects in the MBDC suggests that the multiple question format does not cause concerns (Vossler et al. 2004).

\subsection{Data Collection}

The six Australian cities chosen to draw Sample 2 were the same as those used in Sample 1 in Cooper et al. (2011). The questionnaire was distributed online to a random sample of households and at the time of distribution $79 \%$ of Australian households had home internet access (Australian Bureau of Statistics 2012). This mode of data collection has a number of advantages and disadvantages over alternatives (see Fleming and Bowden 2009). As described in Sect. 2, these cities provided opportunity for analysis across a number of dimensions, including comparisons between cities in the states of Victoria and New South Wales; and 
Table 2 Characteristics of study locations

\begin{tabular}{lllll}
\hline City & State & $\begin{array}{l}\text { Rural or metropolitan } \\
\text { centre }\end{array}$ & Population ${ }^{\dagger}$ & $\begin{array}{l}\text { Average annual residential water } \\
\text { supplied for the period 2011-2012 } \\
{[\mathrm{kL} / \text { property }]^{\grave{A}}}\end{array}$ \\
\hline Melbourne & Victoria & Metropolitan & 4.2 million & 142 \\
Wodonga & Victoria & Rural & 38452 & 179 \\
Bendigo & Victoria & Rural & 103722 & 165 \\
Goulburn & NSW & Rural & 28721 & 138 \\
Albury & NSW & Rural & 49655 & 203 \\
Sydney & NSW & Metropolitan & 4.6 million & 193 \\
\hline
\end{tabular}

$\dagger$ Source: Australian Bureau of Statistics (2013)

$\grave{A}$ This indicator is derived from dividing the total volume of residential water supplied with the number of connected residential water properties (Source: National Water Commission 2012)

Table 3 Socio-demographics of the survey sample

\begin{tabular}{|c|c|c|}
\hline & $\begin{array}{l}\text { Sample } 1 \text { (collected } 2008- \\
\text { during drought, see Cooper et al. } \\
2011)\end{array}$ & $\begin{array}{l}\text { Sample 2(collected 2012-post } \\
\text { drought) }\end{array}$ \\
\hline New South Wales & $48 \%$ & $46 \%$ \\
\hline Victoria & $52 \%$ & $54 \%$ \\
\hline Average age & 42 years & 42 years \\
\hline $\begin{array}{l}\text { Average household } \\
\text { income before tax }\end{array}$ & \$978/week & $\$ 1065 /$ week \\
\hline Homeowner & $30 \%$ & $63 \%$ \\
\hline Male & $40 \%$ & $41 \%$ \\
\hline $\begin{array}{l}\text { Completed a tertiary } \\
\text { degree }\end{array}$ & $34 \%$ & $45 \%$ \\
\hline $\begin{array}{l}\text { Have a lawn and/or } \\
\text { garden that requires } \\
\text { watering }\end{array}$ & $85 \%$ & $64 \%$ \\
\hline $\begin{array}{l}\text { Have an outdoor pool } \\
\text { or spa }\end{array}$ & $15 \%$ & $14 \%$ \\
\hline
\end{tabular}

regional and metropolitan cities. In this case Sample 2 comprised 643 respondents (Wodonga: 31; Albury: 23; Melbourne: 247; Sydney: 250; Goulburn: 25; Bendigo: 67). Table 2 highlights some relevant characteristics of the study locations.

The data for Sample 2 were collected in October 2012 and the questionnaire realised a response rate for the questionnaire of 45 per cent. Details of the sample are reported in Table 3, along with equivalent data for the 2008 sample (Sample 1).

The greatest difference in the demographics of the samples is the increase in the number of homeowners (as opposed to renters) and a reduction in the number who have a lawn/garden that requires watering. It should be noted that in Australia most housing and council association landlords require tenants to maintain outdoor spaces such as lawns, gardens and pools where a penalty on exit is applied if renters do not comply, so that behaviour between renters and homeowners may be expected to be similar. Whilst it is not possible to definitively explain 
the over representation of home ownership in Sample 2, it is worth noting that at the end of 2008 the Australian government provided a boost to the first home buyer scheme to stimulate the housing market.

The arrangements for tenants regarding water bill payments differ slightly across the two states in this study. To accommodate this, it was made clear to respondents that any changes in water prices not directly borne by a tenant would manifest in equivalent payments in rental payments.

The survey consisted of four parts with the first containing questions regarding respondents' attitude toward a number of water related issues and their attitude toward risks. Social and psychological cognitive models imply that attitudes perform a significant part in the individual's behaviour (Armitage and Conner 2001) and as mentioned noted earlier, Cooper et al. (2011) found evidence that attitudinal variables have a significant impact on preferences towards water restrictions. Accordingly, the first part of the survey contained questions where participants were required to rate their agreement with a series of attitudinal statements using a 7-point Likert scales. These questions were developed to ascertain several important attitudes, including general attitudes towards climate change and water trade, values towards the environment, and attitudes towards risk behaviour. Additional explanation of these variables appears in "Appendix B". A choice experiment focusing on preferences for product choice in the urban water sector was presented in the second part of the questionnaire, however this data is not considered here. ${ }^{1}$ Questions pertaining to the respondents' socio-economic status were included in part three of the questionnaire. The final section was used to probe respondents' WTP to avoid water restrictions using the MBDC CV question.

\section{Finite Mixture Model, Scaled Ordered Probit}

WTP estimates can be retrieved from these data in a number of ways and in this case we applied an ordered probit model, following Cameron et al. (2002), Horna et al. (2007) and Cooper et al. (2011). Given the objective of this paper is to compare results from similar surveys across two climatic backdrops, we implement the same statistical model as outlined in Cooper et al. (2011), and the exposition below draws heavily on Sect. 3.3 of that paper, although we note that alternative approaches to dealing with the interval nature of this data have been proposed (e.g. Kobayashi et al. 2012). The observed dependent variable is coded from -2 through +2 for "definitely no", "probably no", "not sure", "probably yes", and "definitely yes" respectively (see "Appendix A"). Probit models are premised on the existence of an underlying continuous variable, $y^{*}$, being a linear combination of some predictors, $x$. The predictors include the bid amount, $(B I D)$, plus a disturbance term that has a standard Normal distribution and is thus characterized by Eq. 2:

$$
y_{i}^{*}=x_{i} \beta+\beta_{0} B I D+\varepsilon_{i}, \varepsilon_{i} \sim N(0,1) \forall i=1, \ldots N
$$

In Eq. (2) yi represents the observed ordinal variable for individual i which takes on integer values from 0 to $m$ according to the 'cut values' for each level.

Formally, the cut values are represented by Eq. (3) below:

$$
y_{i}=j \Leftrightarrow \mu_{j-1}<y_{i}^{*} \leq \mu_{j}
$$

\footnotetext{
1 We acknowledge that including multiple valuation questions in the same questionnaire could potentially impact on responses (e.g. Day and Prades 2010), in this case, it was not feasible to test for sequencing effects by implementing split designs.
} 
where $j=0, \ldots, \mathrm{m}$, and $\mu_{-1}=-\infty$, and $\mu_{m}=+\infty$, and the $\mu_{j}$ are defined as the 'cut values'.

The probability of observing a particular ordinal outcome is given by:

$$
P\left(y_{i}=j\right)=\Phi\left(\mu_{j}-x_{i} \beta-\beta_{0} B I D\right)-\Phi\left(\mu_{j-1}-x_{i} \beta-\beta_{0} B I D\right)
$$

Maximum likelihood estimation (MLE) is used to estimate the model. Defining an indicator variable $Z i j$, which equals 1 if $y i=j$ and 0 otherwise, the log-likelihood is given by:

$$
\ln \mathbf{L}=\sum_{i=1}^{N} \sum_{j=0}^{m} Z i j \ln [\Phi i j-\Phi i, j-1]
$$

where

$$
\Phi_{i j}=\Phi\left(\mu_{j}-x_{i} \beta-\beta_{0} B I D\right) \text { and } \Phi_{i j-1}=\Phi\left(\mu_{j-1}-x_{i} \beta-\beta_{0} B I D\right) \quad \text { [Greene 1990] }
$$

Estimation was undertaken using the GLLAMM (generalized linear latent and mixed models) subroutine (Rabe-Hesketh 2004) within Stata 13 (StataCorp. 2013). As noted by Kobayashi et al. (2012), it is unlikely that the density for each individual will follow the same distribution, even given the observable heterogeneity represented by individual specific variables $x_{i}$. Our approach to accounting for unobservable heterogeneity is to modify the error term in [2] in two ways. The first is to introduce an individual specific error component, so that the model becomes a random effects ordered probit model. Further, the distribution of this random effect does not follow a single normal distribution, but a latent mixture of two normal distributions:

$y_{k i}^{*}=x_{i} \beta+\beta_{0} B I D_{k}+\zeta_{i}+\varepsilon_{k i}, \varepsilon_{k i} \sim \mathrm{N}\left(0, \sigma_{s}^{2}\right), \zeta_{i} \sim p_{1} \mathrm{~N}\left(m_{1}, \sigma_{c l}^{2}\right)+\left(1-p_{1}\right) \mathrm{N}\left(m_{2}, 1\right)$

where $\zeta_{\mathrm{i}}$ represents an individual specific random effect, and $\mathrm{k}[1, \ldots 12]$ correspond to the bid. Responses are thus correlated for an individual, but are independent across individuals (Alberini et al. 2003). Making the individual specific effects $\zeta_{i}$ a finite mixture of two normals, with different means $\mathrm{m}_{1}, \mathrm{~m}_{2}$ allows responses to bid values to be quite different across sections of the sample. For example, if the mean of one of the error distributions [i.e. m1, m2] takes on a large negative value, the probability of rejecting any given bid can approach 1 . Implicitly this allows for a rejection of the tradeoffs implied by the ordered probit model, and to have a mass of individuals at a corner solution, of not being prepared to pay any amount to avoid water restrictions with any level of certainty. The proportion who might fall into this group is determined by the estimated mixing probabilities (of $p_{1}$ and $\left[1-p_{1}\right]$ ) of being in each class. It is also possible to parameterize class membership using observed characteristics of the individual applying a logit functional form.

Identification requires restrictions to the error process. More specifically, the expected value of the means is zero (i.e $\mathrm{p}_{1} \mathrm{~m}_{1}+\left[1-\mathrm{p}_{1}\right] \mathrm{m}_{2}=0$ ). If covariates are included to explain class membership, this constraint is imposed at the point where all covariates are zero. Similarly, one variance term is required to be constrained to unity to allow the other to be freely estimated $\left[\sigma_{c l}^{2}\right]$.

Finally, heterogeneity in the variance of the non-individual-specific random component $\varepsilon_{k i}$ is also allowed for i.e. the degree of uncertainty in individual selections of outcomes for each bid amount. The scaled ordered probit caters for this by parameterizing the variance $\sigma_{s}^{2}$ as a function of individual characteristics (Cooper et al. 2011). 
Overall the model can give a very rich representation of behaviour. Individual specific observable characteristics in the vector $x_{i}$ can account for systematic differences in WTP due to personal characteristics, geographical location or time. The random effects error term acknowledges that there may be unobservable effects that shift individuals WTP, and allowing those to be bimodal allows for greater flexibility, and the possibility that some respondents may reject all bids and not be prepared to pay any amount to avoid water restrictions. However, such an effect is determined by the data, and individuals would be assigned to such behaviour probabilistically, rather than ex ante.

\section{Findings}

Two finite mixture, scaled ordered probit models (as described in Sect. 4) were estimated. Firstly, the data set from Sample 1 (Cooper et al. 2011) and Sample 2 (as described in Sect. 3) were pooled and a relatively simple model estimated to allow identification of changes in WTP across the 4 year period. Secondly, a more complex model was estimated using data from Sample 2 only, incorporating socio-demographic variables to provide insight into the heterogeneity of household WTP to avoid water restrictions and highlight why bids may have changed over time.

\subsection{Comparison Finite Mixture, Scaled Ordered Probit Model: Pooling CV Data}

In this first analysis, the data from both Sample 1 and Sample 2 is pooled. There is not a full matching set of socio demographic variables in both samples, so it is not possible to replicate the model published in Cooper et al. (2011) with the current sample. Those variables that are jointly available (Table 2) are tested in the model. The two effects that are found to be significant are having a lawn or garden that needs watering, and income. A dummy for year of sampling is included for the bid amount, cutpoints and city effects, allowing for considerable flexibility in how any temporal effects may influence choices.

Table 4 presents the results of the scaled ordered probit model. The model allows the WTP to avoid restrictions to vary by city, and for that impact to vary across time. In this model, the city of Sydney has been used as the baseline case. The error variance and the probability of class membership are also allowed to vary by sample through the introduction of SAMPLE 2 , a dummy variable which takes a value of 1 if an observation is from the post drought sample (Sample 2), and 0 otherwise.

Inclusion of the mixture model for the individual specific random effects provides two mass points, with means at -1.774 and 0.671 . For Sample 1 the prior probabilities are 0.27 and 0.73 , respectively. The first mass point is sufficiently negative for the probability of giving a "definitely no" answer to even a zero bid amount to be very high. Members of this class (class 1 ) tend not to show any response to the bids, consistent with a protest against the proposal to avoid water restrictions through a basic monetary payment, or individuals who are indifferent about the consequence of restrictions. We do not introduce any individual sociodemographics to explain membership of this class, but the positive coefficient for Sample 2 [SAMPLE2] in the class membership logit model implies that the probability of being a member of the group that has a zero WTP for removing water restrictions (class 1) is greater in the second sample: it increases from 0.27 to 0.35 . When considering the changes in WTP of class 2 reported later, this result should be remembered: there is an increase in the number of respondents for whom the WTP to avoid water restrictions is zero. 
Table 4 Comparison model: ordered probit model of WTP to avoid water restrictions using pooled data from Samples 1 and 2
*** indicates significance at the 1 percent level. ** indicates significance at the 5 percent level. * at $10 \%$ level.

$\$$ Odds ratio for effect in parenthesis

\begin{tabular}{|c|c|c|}
\hline & Coefficient & Z statistic \\
\hline BID & $-0.0038^{* * *}$ & 38.57 \\
\hline BID_SAMPLE 2 & -0.00007 & 0.44 \\
\hline INCOME & $0.000258 * * *$ & 7.80 \\
\hline LAWN & $0.0823 * *$ & 2.39 \\
\hline WODONGA & -0.048 & 0.74 \\
\hline WODONGA_SAMPLE 2 & $-0.385^{* * *}$ & 3.53 \\
\hline MELBOURNE & -0.026 & 0.40 \\
\hline MELBOURNE_SAMPLE 2 & -0.018 & 0.22 \\
\hline BENDIGO & 0.105 & 1.74 \\
\hline BENDIGO_SAMPLE 2 & $-0.243^{* *}$ & 2.54 \\
\hline GOULBURN & 0.019 & 0.25 \\
\hline GOULBURN_SAMPLE 1 & -0.026 & 0.18 \\
\hline ALBURY & $0.140 * *$ & 2.22 \\
\hline ALBURY_SAMPLE 1 & $-0.415^{* * *}$ & 3.49 \\
\hline \multicolumn{3}{|l|}{ Cut points } \\
\hline$\mu_{1}$ [SAMPLE 2] & $-0.384 * * *$ & 4.83 \\
\hline$\mu_{1}[$ Constant $]$ & $-0.313^{* * *}$ & 3.61 \\
\hline$\mu_{2}$ [SAMPLE 2] & $-0.309 * * *$ & 4.35 \\
\hline$\mu_{2}[$ Constant $]$ & 0.104 & 1.20 \\
\hline$\mu_{3}[$ SAMPLE 2] & $-0.151^{* *}$ & 2.42 \\
\hline$\mu_{3}[$ Constant $]$ & $0.534 * * *$ & 6.20 \\
\hline$\mu_{4}[$ SAMPLE 2] & -0.096 & 1.64 \\
\hline$\mu_{4}[$ Constant $]$ & $1.04 * * *$ & 12.74 \\
\hline \multicolumn{3}{|c|}{ Scale equation [log standard deviation] } \\
\hline SAMPLE2 & $1.515^{* * *}$ & 15.45 \\
\hline \multicolumn{3}{|l|}{ Random effects } \\
\hline & Class 1 & Class 2 \\
\hline $\mathrm{m}_{1}: \mathrm{m}_{2}$ & -1.774 & 0.671 \\
\hline \multicolumn{3}{|l|}{ Log odds parameters [class 1] } \\
\hline SAMPLE 2 & $0.347(1.415)^{\$}$ & 2.553 \\
\hline constant & -1.01 & 9.623 \\
\hline Log Likelihood & -14518.996 & \\
\hline Number of Observations & 13771 & \\
\hline Number of Individuals & 1154 & \\
\hline McFadden Pseudo R2 & 0.13 & \\
\hline
\end{tabular}

The coefficients on income and lawn imply that those who have higher incomes, and who have a lawn that requires watering, will have higher WTP to avoid restrictions.

\subsection{Comparison of WTP to Avoid Water Restrictions}

As noted in Cooper et al. (2011) the definition of the median WTP is complex if the middle category of the MBDC question is "unsure." In such instances the median WTP can only be expressed as falling within a bound. These are defined in this case as 
Table 5 Median WTP (conservative estimates): Samples 1 and 2 combined

\begin{tabular}{llllll}
\hline & $\begin{array}{l}\text { Sample 1: 2008 data } \\
\text { C1 }\end{array}$ & $\begin{array}{l}\text { Sample 2: 2012 data } \\
\text { C2\% }\end{array}$ & $\begin{array}{l}P \text { value } \\
\text { C3 }\end{array}$ & $\begin{array}{l}\text { Sample 2: 2012 data } \\
\text { C4^ }\end{array}$ & $\begin{array}{l}P \text { value } \\
C^{\circledR}\end{array}$ \\
\hline Wodonga & $110^{* * *}$ & $48^{*}$ & 0.04 & $48^{*}$ & 0.04 \\
Melbourne & $131 * * *$ & $162 * * *$ & 0.06 & $130 * * *$ & 0.98 \\
Bendigo & $148^{* * *}$ & $122 * * *$ & 0.20 & $105 * * *$ & 0.03 \\
Goulburn & $134 * * *$ & $164 * * *$ & 0.37 & $126 * * *$ & 0.77 \\
Albury & $165 * * *$ & $95 * * *$ & 0.01 & $86^{* * *}$ & 0.00 \\
Sydney & $137 * * *$ & $170 * * *$ & 0.02 & $141^{* * *}$ & 0.80 \\
\hline
\end{tabular}

$*, * * * * *$ indicate $10,5,1 \%$ significance levels. \% WTP in 2012, maintaining sociodemographics at mean 2008 values $\$ P$ value for null hypothesis that WTP in $\mathrm{C} 1$ and $\mathrm{C} 2$ are equal ${ }^{\wedge} \mathrm{WTP}$ in 2012 , maintaining sociodemographics at mean 2008 values, and adjusting for regional house price inflation (source: RealEstate2017; ABS 2017) @P value for null hypothesis that WTP in C1 and C4 are equal

$$
W T P_{l}=\left[x_{i} \beta-\mu_{3}\right] / \beta_{0}
$$

and

$$
W T P_{u}=\left[x_{i} \beta-\mu_{2}\right] / \beta_{0}
$$

where 1 and $u$ indicate lower and upper bounds respectively.

One perspective of these bounds is that they represent alternative interpretations of the value required to reach a majority in a referendum: the lower assumes that the majority can include only those who say "definitely yes" and "probably yes," while the upper bound considers those who respond "definitely yes," "probably yes," and also "uncertain" (Cooper et al. 2011). The inclusion of respondent-specific exogenous variables $x_{i}$, allows for the WTP values to be evaluated either at the means of the variables, or at specific values.

Given the way that the temporal dummy SAMPLE_2 is introduced into the model, shifts in the WTP for any city can be caused by any of 4 effects across the two time periods: changes in the bid coefficient, changes in the cut points, changes in city specific effects, and changes in levels of sociodemographic variables across the two time periods.

Table 5 presents the conservative (i.e. smaller) median WTP estimates for both Sample 1 (drought: column C1) and Sample 2 (post drought study: C2) from the pooled model. Given we have individual socio-demographics in the model, estimates of WTP have to be conditioned on these values. We use the city specific mean values, for the 2008 sample. In this way we control for the impact of changes in these variables across the two time periods on WTP. The WTP values are estimated for each of the cities, conditional upon holding these sociodemographics fixed, and a test conducted to identify if there is a significant difference across the two samples, using the delta method ( $P$ value reported in C3). It is important to note that these WTP values are estimated conditional upon being a member of class 2 , which are those who are prepared to pay to avoid restrictions. It should be recalled that the probability of being in this class fell in the post drought Sample 2 from 0.73 to 0.65 .

However, one could also argue that the WTP estimates are conditional upon house prices i.e. where house prices increase, this will lead to a higher WTP as one is prepared to pay more to avoid water restrictions that will impact on the value of the asset. ${ }^{2}$ House prices also feature prominently in the press and Australian public policy increases the focus on the price of dwellings. Although the model corrects for differences in personal incomes, this

2 We thank a reviewer who suggested this possibility. 
may not reflect differences in house prices across time, and we have no data on individual property values in the survey. We therefore employ a post-estimation adjustment to account for these effects. C4 in Table 5 reports estimates of 2012 WTP estimates, deflated by the regional house price change i.e. $\mathrm{C} 4$ holds both individual incomes and regional house prices at 2008 levels. Once adjusted for house price increases, the significant increase in WTP recorded for Melbourne and Sydney in C3 become insignificant in C5: there is no evidence that the breaking of the drought has changed perspectives of water restrictions in these cities. What were identified previously as regional cities with better water availability (Wodonga and Albury) have significant declines in WTP on either basis. If one takes the house price adjusted estimate (C4), Bendigo, a regional city, also shows a decline in WTP, while Goulburn shows no decline. What is notable about these two cities is that the severe water restrictions that the residents of Bendigo confronted for 8 years were relaxed in January 2011, while the severe water restrictions that the residents of Goulburn faced on level 5 were not removed, but only relaxed to level 3 (Table 1).

Essentially, there is not a consistent change in WTP values against the background of drought and non-drought, but there are possible patterns that are associated with metropolitan versus regional cities. Further investigation into what might be potentially driving WTP in Sample 2 may provide additional insight into these preferences. To undertake this task additional modelling of Sample 2 occurred and is described in the following section.

\subsection{Finite Mixture, Scaled Ordered Probit Model: Post Drought Analysis}

Table 6 presents the results of the finite mixture, scaled ordered probit model that was estimated from Sample 2 only, the post drought data collection described in Sect. 3.2. In this model, significant socioeconomic and attitude items have been included to improve model fit and investigate what variables are driving WTP. As it was not compulsory to answer all of the socioeconomic questions, the inclusion of these variables reduces the available sample size to 621, mainly due to refusal to report income levels. "Appendix B" provides an explanation of the attitudinal variables. There are three different parts of the model where covariates can be considered: the bid equation, the error scale equation, and the class membership equation (Cooper et al. 2011). The findings that appear here are the result of a search for alternative specifications, however, all of the results outlined here are robust, in so far as their significance does not vary with alternative specifications of the model.

The model indicates that a number of socioeconomic variables are significant determinants of WTP: having a higher income [INCOME], and a lower number of residents in the house [RESIDENTS] all lead to greater WTP. The model also indicates that several attitudinal variables are significant determinants of WTP: those who expressed strong support for the carbon tax [CARBON TAX]; supporters of water trade between urban and rural sectors [WATER TRADE]; respondents who placed high importance on the need to invest in securing their city's water supply [SUPPLY]; supporters of the view that climate change would impact on the uncertainty of water security [CLIMATE CHANGE]; those who were risk seeking [RISK]; and those who had strong environmental values all had higher WTP values. Alternatively, those who indicated that restrictions were effective in addressing water shortages [RESTRICTIONS] and were more likely to comply with restrictions [COMPLY] had a lower WTP. Moreover, the model suggests that Wodonga [WODONGA], Melbourne [MELBOURNE], Bendigo [BENDIGO] and Albury [ALBURY] have a lower WTP than respondents from Sydney, while Goulburn [GOULBURN] residents do not have a significantly different WTP to Sydney. 
Table 6 Finite mixture, scaled ordered probit model of WTP to avoid water restrictions: Sample 2 data only
*** Indicates significance at the $1 \%$ level. ** Indicates significance at the $5 \%$ level. *at $10 \%$ level. $\$$ Odds ratio for effect in parenthesis

\begin{tabular}{|c|c|c|}
\hline & Coefficient & Z statistic \\
\hline BID & $-0.003 * * *$ & 35.00 \\
\hline RESTRICTIONS & $-0.061 * * *$ & 3.50 \\
\hline CARBON TAX & $0.028 * *$ & 2.12 \\
\hline WATER TRADE & $0.046 * * *$ & 3.00 \\
\hline SUPPLY & $0.113 * * *$ & 6.13 \\
\hline INCOME & $0.88 \mathrm{E}-04 * *$ & 2.17 \\
\hline RESIDENTS & $-0.053 *$ & 1.89 \\
\hline COMPLY & $-0.041 * *$ & 2.30 \\
\hline CLIMATE CHANGE & $0.119 * * *$ & 5.16 \\
\hline RISK & $0.118^{* * * *}$ & 5.97 \\
\hline E-VALUES & $0.081 * * *$ & 3.20 \\
\hline WODONGA & $-0.212 * *$ & 2.31 \\
\hline MELBOURNE & $-0.088 * *$ & 2.18 \\
\hline BENDIGO & $-0.110^{*}$ & 1.90 \\
\hline GOULBURN & 0.142 & 1.41 \\
\hline ALBURY & $-0.234 * * *$ & 2.63 \\
\hline \multicolumn{3}{|l|}{ Cut points } \\
\hline$\mu_{1}$ & 0.354 & 1.48 \\
\hline$\mu_{2}$ & $0.783 * * *$ & 3.27 \\
\hline$\mu_{3}$ & $1.306^{* * *}$ & 5.44 \\
\hline$\mu_{4}$ & $1.860 * * *$ & 7.69 \\
\hline \multicolumn{3}{|c|}{ Scale equation [log standard deviation] } \\
\hline UNDERSTAND & 0.047 & 3.13 \\
\hline RISK & -0.032 & 2.66 \\
\hline \multicolumn{3}{|l|}{ Random effects } \\
\hline & Class 1 & Class 2 \\
\hline $\mathrm{m} 1: \mathrm{m}_{2}$ & 1.304 & -0.886 \\
\hline \multicolumn{3}{|c|}{ Log odds parameters [class 1] } \\
\hline RIGHT_1 & $0.428(1.534)^{\$}$ & 1.60 \\
\hline RIGHT_2 & $1.109(3.031)$ & 3.30 \\
\hline RISK & $0.430(1.537)$ & 4.02 \\
\hline RESTRICTIONS & $0.132(1.141)$ & 2.11 \\
\hline constant & -0.386 & 1.04 \\
\hline Log Likelihood & -8149.145 & \\
\hline Number of Observations & 7412 & \\
\hline Number of Individuals & 621 & \\
\hline McFadden Pseudo R2 & 0.16 & \\
\hline
\end{tabular}

The parameterization of the variance indicates two significant effects: being able to understand the survey [UNDERSTAND] and having a higher tendency to take risk [RISK]. Essentially, having a high understanding of the survey and a tendency to engage in more risky behaviour reduced the predictability of the individual's response to any specific question. In other words, for any given bid amount, there is a "most probable" response, but this 
probability is smaller for those who indicate that they understood the survey and those who are more risk seeking.

The introduction of the mixture model for the individual specific random effects provides two mass points, with means at 1.304 and -0.886 . The implication is that the model has 2 latent classes with quite different behaviours. The mass point for class 2 is sufficiently negative for the probability of giving a "definitely no" response to even a zero bid amount to be very high (see discussion below). Membership of class 2 indicates this group does not demonstrate any response to the bids, consistent with a protest vote. Alternatively, members of this class can be considered to be indifferent about the consequences of restrictions.

When evaluated at the mean of the sociodemographic variables, the probability of being a member of the class who is not prepared to pay to avoid restrictions is 0.36 , which is very close to that reported for the comparative model in 5.1 above. $^{3}$ The logit model for membership shows that those who believe that water utilities have the right to impose water restrictions [RIGHT_1] and those who are uncertain about whether water utilities have the right to impose water restrictions [RIGHT_2] were more likely to be members of the class that were willing to buy their way out of water restrictions [class 1]. The later has a particularly strong effect on class membership, with an odds ratio coefficient of 3.03. Those who believe that water restrictions are effective in addressing water shortages [RESTRICTIONS] were also more likely to be members of the class that were willing to make trade-offs i.e. make a payment to alleviate the burden of water restrictions [class 1].

Subsequent to model estimation, empirical Bayes estimates of the posterior probabilities of class membership for each individual can be generated [using the gllapred command] (Rabe-Hesketh 2004, p.27). Evaluation of these suggests that class membership is very clearly defined: only $5 \%$ of the sample had a maximal posterior probability of class membership less than $96 \%$.

\subsection{WTP to Avoid Water Restrictions Post Drought}

As discussed in Sect. 5.2, the median WTP values can subsequently be estimated. One needs to make assumptions about the levels of the socio-demographic variables at which to evaluate these medians. Table 7 presents both the liberal and conservative estimates for the latest data collection for each city, while holding all other variables at the city specific means. The estimates are conditional upon being in class 1 (i.e. those who do not reject avoiding restrictions out of principle). These values are useful in that they give an estimate of the WTP for an average respondent from the city i.e. it includes both city specific effects but also heterogeneity in attitudes etc. across the cities.

The mean values for the exogenous variables, by city, appear in "Appendix C". The marginal effects, which are the dollar changes in WTP for a unit changes in the significant exogenous variables that appear in Table 7 are presented in "Appendix C" also.

Figures 1 and 2 illustrate the predicted probabilities for each outcome (definitely no; probably no; unsure; probably yes; definitely yes) for each of the bid amounts, conditional upon being in class 1 and class 2, respectively. These are averages across Sample 2. As the bid amount rises, the probability of being willing to pay falls i.e. at $\$ 150$ approximately $50 \%$ would say no or are unsure. The propensity of class 2 to act as a protest group, and not being prepared to make any payment to avoid restrictions at even low bids is clearly displayed here, with a very high probability of giving a "no" or "definitely no" response to a bid amount of $\$ 0$. This result is a consequence of the large -ve mass point in Table 6.

\footnotetext{
3 Note that the addition of covariates influences the parameter estimates in the class membership model, but what is relevant is the implied probabilities.
} 
Table 7 Median WTP (liberal and conservative estimates) for Sample 2, class 1

$*, * *, * * *$ Indicate $10,5,1 \%$ significance levels

\begin{tabular}{lcc}
\hline & Conservative & Liberal \\
\hline Wodonga & 41 & $200 * * *$ \\
Melbourne & $128 * * *$ & $288 * * *$ \\
Bendigo & $89 * * *$ & $248 * * *$ \\
Goulburn & $153 * * *$ & $313 * * *$ \\
Albury & $76 * * *$ & $236 * * *$ \\
Sydney & $151 * * *$ & $311 * * *$ \\
\hline
\end{tabular}

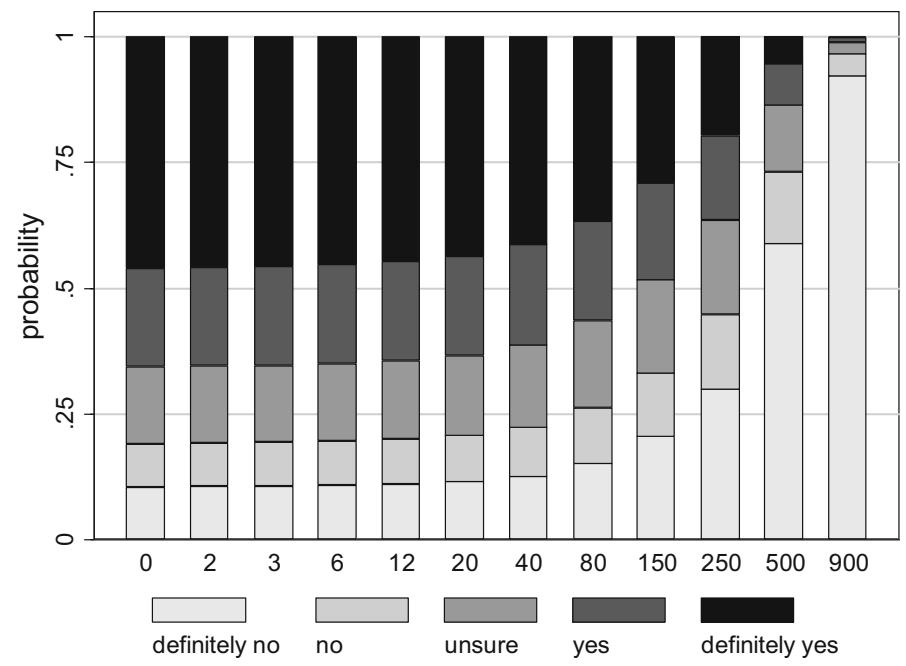

Fig. 1 Predicted probabilities of being willing to pay to avoid water restrictions by bid level: Class 1, 2012 sample

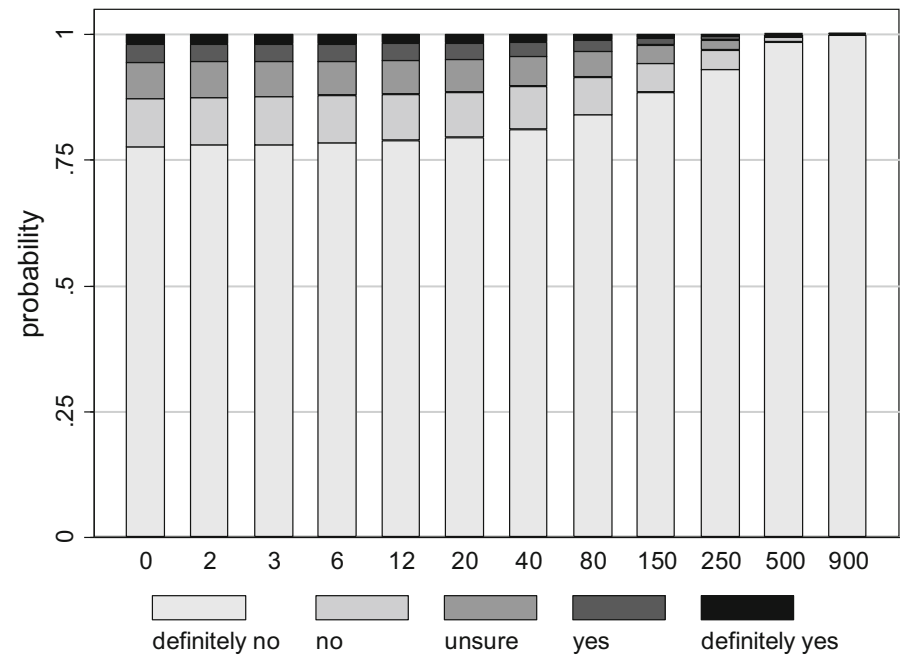

Fig. 2 Predicted probabilities of being willing to pay to avoid water restrictions by bid level: Class 2, 2012 sample 
Table 8 Median WTP [conservative estimates]

\begin{tabular}{|c|c|c|c|c|c|c|}
\hline \multirow[t]{2}{*}{ City } & \multicolumn{3}{|l|}{2008} & \multicolumn{3}{|l|}{2012} \\
\hline & Households $^{a}$ & WTP & Aggregate WTP '000 & Households ${ }^{a}$ & WTP & Aggregate WTP '000 \\
\hline Wodonga & 11,112 & 110 & 892 & 14,719 & 43 & 411 \\
\hline Bendigo & 28,900 & 148 & 3122 & 35,719 & 125 & 2902 \\
\hline Albury & 17,634 & 165 & 2124 & 20,732 & 90 & 1213 \\
\hline
\end{tabular}

a Australian Bureau of Statistics (2006, 2011)

\section{Discussion and Concluding Remarks}

One of the primary objectives of this study was to investigate if there was a significant difference in the WTP values when there is a different climate setting. Sample 1 related to a survey conducted during a period of prolonged drought and Sample 2 related to post drought, 4 years after the initial data collection. The study also sought to investigate the variables driving respondents WTP in Sample 2 in order to shed light on potential influences that change utility gained from avoiding water restrictions.

To achieve this, the data from the study conducted by Cooper et al. (2011) was used (Sample 1) and an additional MBDC CV experiment was conducted in 2012 post drought (Sample 2). Both of these studies used identical MBDC response formats to allow for data to be pooled and meaningful comparisons made. The results in the initial basic comparison model, where sociodemographics are maintained at mean 2008 values, show that there is a significant difference in the WTP values for a number of cities (Albury, Wodonga, Melbourne, and Sydney) across the studies. However, when we also adjust for regional house price inflation, there is a significant difference in the WTP values for most of the regional cities (Albury, Wodonga, and Bendigo) but no significant change in the bids offered in metropolitan settings, and for Goulburn, which is the regional city that has retained the highest level of restrictions into 2012. Accordingly, we might tentatively posit that climatic context appears to matter more in some regional settings than metropolitan areas, once we account for changes in the value of housing assets.

From a policy perspective, these results are important. As we noted earlier major water infrastructure projects have been commissioned in response to prolonged drought in countries like Australia and the perceived costs borne by water users. Part of the rationale for these projects rests on the assumption that mandatory water restrictions impose welfare losses on households and, ceteris paribus, households would be willing to pay to avoid the imposts. Moreover, stated preference studies are continuing to be deployed to enumerate the 'value' of water infrastructure that is not climate-dependents. This study supports the view that willingness to pay estimates of this form can materially change when the climatic setting is altered in at least some locales.

To give some indication of the monetary impacts of these changes we have converted the different estimates into potential aggregated community values (Table 8). For simplicity we report only the changes in aggregate values from a conservative perspective and only in those locations where estimates change, whilst holding property values constant. Given the estimated model identifies a protest group who have a zero median WTP, a decision has to be made on how to include this group. If this group are genuinely indifferent about the imposition of water restrictions, then one could assume that 27 and $35 \%$ of the sample have zero WTP, and weight the estimates in Table 5 accordingly. If this group are a protest 
against the payment mechanism then one can potentially assume that they would have the same average WTP as the rest of the sample. We maintain our conservative approach to estimating WTP, and assume that the 'protest' group have zero WTP. What this shows is that for a relatively small community like Albury, the costs of some augmentation projects, like localised water recycling costing \$2 million, may exceed or fall short of benefits, depending on when estimates are formulated.

In order to shed light on the possible motivations for altered WTP bids a finite mixture, scaled ordered probit model was developed using the more recent data. In this model, the extension to the representation of the error process has been justified, with significant error variance heterogeneity identified, and relatively different behavioural responses identified for two latent classes within the sample [Sample 2]. Notably, the model allowed for a segment who are indifferent to being offered the option to avoid water restrictions. The results also imply that individual's sensitivity to water restrictions appear to vary between groups within the population. Recognising the segments within the population who are most willing to pay to avoid water restriction is an important part to developing effective policy.

Clearly, elements of this research raise questions that require further investigation. For example, whilst the finite mixture, ordered probit model provides some indication of the motivations that shape WTP, the apparent 'city effect' requires further investigation.

Open Access This article is distributed under the terms of the Creative Commons Attribution 4.0 International License (http://creativecommons.org/licenses/by/4.0/), which permits unrestricted use, distribution, and reproduction in any medium, provided you give appropriate credit to the original author(s) and the source, provide a link to the Creative Commons license, and indicate if changes were made.

\section{Appendix A: Bid Design}

Reported below is the question introduction and bid grid used in both surveys.

Given your household's income and other expenses, we would like you to think about whether or not you would be willing to make an annual payment so your household would not be subject to water restrictions. This amount would be listed as a separate item on one of your water bills for the year.

For each of the amounts below, please indicate your willingness to pay to avoid water restrictions. 


\begin{tabular}{llllll}
\hline \multirow{2}{*}{ Amount (each year) } & \multicolumn{5}{c}{ Willingness to Pay? } \\
\cline { 2 - 6 } & Definitely no. & Probably no. & Not sure & Probably yes & Definitely yes \\
\hline 0 & A & B & C & D & E \\
$\$ 2$ & A & B & C & D & E \\
$\$ 3$ & A & B & C & D & E \\
$\$ 6$ & A & B & C & D & E \\
$\$ 12$ & A & B & C & D & E \\
$\$ 20$ & A & B & C & D & E \\
$\$ 40$ & A & B & C & D & E \\
$\$ 80$ & A & B & C & D & E \\
$\$ 150$ & A & B & C & D & E \\
$\$ 250$ & A & B & C & D & E \\
$\$ 500$ & A & B & C & D & E \\
$\$ 900$ & A & B & C & D & E \\
More than the above & A & B & C & D & E \\
\hline
\end{tabular}

\section{Appendix B: Coding of Interactions Variables}

The following tables report the socio-demographic variables (Table 9), and the factors (Table 10) used in the model. 
Table 9 Interaction variables used in the model

\begin{tabular}{|c|c|c|}
\hline Variables & Descriptor & Levels/coding \\
\hline RESTRICTIONS & $\begin{array}{l}\text { Please indicate how effective you believe water restric- } \\
\text { tions are in addressing water shortages }\end{array}$ & $\begin{array}{l}1 \text { [Not effective }]=1 \\
2=2 \\
3=3 \\
4=4 \\
5=5 \\
6=6 \\
7 \text { (Extremely effective) }=7\end{array}$ \\
\hline CARBON TAX & How much do you agree with the carbon tax & $\begin{array}{l}1 \text { [Strongly disagree] }=1 \\
2=2 \\
3=3 \\
4=4 \\
5=5 \\
6=6 \\
7 \text { (Strongly agree) }=7\end{array}$ \\
\hline WATER TRADE & $\begin{array}{l}\text { How much do you agree with water trade between the } \\
\text { urban and rural sectors [e.g. irrigators trading their water } \\
\text { allocation or entitlements to urban water utilities for } \\
\text { household use] }\end{array}$ & $\begin{array}{l}1 \text { [Strongly disagree] }=1 \\
2=2 \\
3=3 \\
4=4 \\
5=5 \\
6=6 \\
7 \text { (Strongly agree) }=7\end{array}$ \\
\hline SUPPLY & $\begin{array}{l}\text { How important do you think investing in securing your } \\
\text { city's water supply is }\end{array}$ & $\begin{array}{l}1[\text { Not important }]=1 \\
2=2 \\
3=3 \\
4=4 \\
5=5 \\
6=6 \\
7 \text { (Extremely Important) }=7\end{array}$ \\
\hline INCOME & Total household income per week & $\begin{array}{l}<\$ 200=200 \\
\$ 200-\$ 299=249.5 \\
\$ 300-\$ 399=349.5 \\
\$ 400-\$ 499=449.5 \\
\$ 500-\$ 599=549.5 \\
\$ 600-\$ 699=649.5 \\
\$ 700-\$ 799=749.5 \\
\$ 800-\$ 999=899.5 \\
\$ 1000-\$ 1499=1249.5 \\
\$ 1500+=1500\end{array}$ \\
\hline
\end{tabular}


Table 9 continued

\begin{tabular}{lll}
\hline Variables & Descriptor & Levels/coding \\
\hline RESIDENTS & The number of residents in their household & 1 or $2=1$ \\
& & 3 or $4=2$ \\
& & $5+3$ \\
COMPLY & How often respondents believe their household complies & $<20 \%$ of the time=1 \\
& with water restrictions & $20-40 \%$ of the time $=2$ \\
& $41-70 \%$ of the time $=3$ \\
& $71-89 \%$ of the time $=4$ \\
& $90 \%$ plus $=5$
\end{tabular}

Table 10 Factors used in the model

\begin{tabular}{|c|c|c|c|}
\hline Variable & Desciptor & Example question & Coding \\
\hline $\begin{array}{l}\text { CLIMATE } \\
\text { CHANGE }\end{array}$ & $\begin{array}{l}\text { Attitude toward climate } \\
\text { change: where an increase } \\
\text { in this variable implies a } \\
\text { stronger belief in the effects } \\
\text { of climate change on water } \\
\text { supply }\end{array}$ & $\begin{array}{l}\text { I think that climate change } \\
\text { will lead to water security } \\
\text { problems in my region in } \\
\text { the future }\end{array}$ & $\begin{array}{l}\text { Factor score: } 5 \text { questions [5 } \\
\text { stage Likert scale] were } \\
\text { reduced to a single } \\
\text { CLIMATE CHANGE } \\
\text { variable }\end{array}$ \\
\hline RISK & $\begin{array}{l}\text { Attitude toward risk: where } \\
\text { an increase in this variable } \\
\text { implies a stronger } \\
\text { propensity to engage in } \\
\text { risky behaviour }\end{array}$ & $\begin{array}{l}\text { Going camping in the } \\
\text { wilderness, beyond the } \\
\text { civilization of a } \\
\text { campground [scale items } \\
\text { adapted from Weber, Blais } \\
\text { and Betz } 2002\end{array}$ & $\begin{array}{l}\text { Factor score: } 42 \text { questions [ } 7 \\
\text { stage Likert scale] were } \\
\text { reduced to a single RISK } \\
\text { variable }\end{array}$ \\
\hline E-VALUES & $\begin{array}{l}\text { Environmental values: where } \\
\text { increased environmental } \\
\text { values implies stronger } \\
\text { values for the environment }\end{array}$ & $\begin{array}{l}\text { It makes me sad to see natura } \\
\text { environments destroyed } \\
\text { [scale items adapted from } \\
\text { Thompson and Barton } \\
\text { 1994] }\end{array}$ & $\begin{array}{l}\text { IFactor score: } 6 \text { questions [7 } \\
\text { stage Likert scale] were } \\
\text { reduced to a single } \\
\text { E-VALUES variable }\end{array}$ \\
\hline
\end{tabular}




\section{Appendix C: Mean values and Marginal Effects}

The marginal effects i.e. partworths from the finite mixture, (Table 11) scaled ordered probit model reported in Table 4 are presented in the Table 12 below. This is the \$ change in WTP for a unit change in the exogenous variable. For the factor variables, CLIMATE CHANGE, RISK and E-VALUES (which are constructed and hence have no units) this is equivalent to a 1 standard deviation change in the variable.

Table 11 Mean values for the exogenous variables, by city

\begin{tabular}{llllllll}
\hline & Wodonga & Melbourne & Bendigo & Goulburn & Albury & Sydney & All \\
\hline RESTRICTIONS & 4.97 & 5.21 & 5.12 & 5.5 & 4.52 & 4.70 & 4.97 \\
CARBON TAX & 2.36 & 3.32 & 3.05 & 2.25 & 3.30 & 3.02 & 3.08 \\
WATER TRADE & 3.37 & 4.25 & 3.81 & 4.00 & 4.00 & 4.02 & 4.07 \\
SUPPLY & 6.09 & 6.06 & 5.91 & 6.46 & 6.00 & 5.94 & 6.01 \\
INCOME & 965 & 1054 & 997 & 933 & 1002 & 1126 & 1065 \\
RESIDENTS & 1.68 & 1.54 & 1.72 & 1.54 & 1.78 & 1.66 & 1.62 \\
COMPLY & 4.61 & 4.39 & 4.41 & 4.75 & 4.04 & 4.37 & 4.40 \\
CLIMATE CHANGE & -0.272 & 0.121 & -0.162 & -0.485 & -0.100 & 0.002 & -0.006 \\
RISK & -0.419 & 0.030 & -0.083 & -0.310 & -0.039 & 0.092 & 0.004 \\
E-VALUES & 0.001 & 0.046 & -0.022 & 0.068 & -0.092 & -0.047 & -0.004 \\
\hline
\end{tabular}

Table 12 Partworths for attributes
$*, * *, * * *$ indicates $10,5,1 \%$ significance levels

\begin{tabular}{lc}
\hline & WTP: \$ per unit change \\
\hline RESTRICTIONS & $-19.60 * * *$ \\
CARBON TAX & $8.55 * * *$ \\
WATER TRADE & $13.99 * * *$ \\
SUPPLY & $34.63 * * *$ \\
INCOME & $0.0269 * *$ \\
RESIDENTS & $-16.21 *$ \\
COMPLY & $-12.47 * *$ \\
CLIMATE CHANGE & $36.50 * * *$ \\
RISK & $36.10 * * *$ \\
E-VALUES & $24.77 * * *$ \\
\hline
\end{tabular}




\section{References}

Alberini A, Boyle K, Welsh M (2003) Analysis of contingent valuation data with multiple bids and response options allowing respondents to express uncertainty. J Environ Econ Manag 45(1):40-62

Allon F, Sofoulis Z (2006) Everyday water: culture in transition. Aust Geogr 37:45-55

Armitage C, Conner M (2001) Efficacy of the theory of planned behaviour: a meta- analytic review. Br J Soc Psychol 40:471-499

Australian Broadcasting Corporation (ABC) News (2008) Manslaughter for fatal punch-up over water, 15 December. Available from URL: http://www.abc.net.au/news/tag/sylvania-2224/. Accessed 7 June 2011

Australian Bureau of Statistics (ABS) (2017) Residential Property Price Indexes. URL: http://www.abs.gov. au/AUSSTATS/abs@nst/DetailsPage/6416.0Mar2017. Accessed 2 Sept 2017

Australian Bureau of Statistics (ABS) (2013) Population by age and sex, regions of Australia, 2012. URL: http://www.abs.gov.au/Ausstats/abs@.nsf/mf/3235.0. Accessed 30 Aug 2013

Australian Bureau of Statistics (ABS) (2012) Household Internet and Computer Access, URL: http://www.abs. gov.au/ausstats/abs@.nsf/Latestproducts/4E4D83E02F39FC32CA25796600152BF4?opendocument. Accessed 7 Jan 2013

Australian Bureau of Statistics (ABS) (2011) Census Community Profiles. URL: http://www.abs.gov.au/ census_services/getproduct/census/2011/quickstat/. Accessed 30 Aug 2017

Australian Bureau of Statistics (ABS) (2006) Census Community Profiles. URL: http://www.abs.gov.au/ census_services/getproduct/census/2006/communityprofile/. Accessed 30 Aug 2013

Barrett G (2004) Water conservation: the role of price and regulation in residential water consumption. Econ Pap 23:271-285

Brennan D, Tapsuwan S, Ingram G (2007) The welfare costs of urban outdoor water restrictions. Aust J Agric Resour Econ 51(3):243-261

Brouwer R (2012) Constructed preference stability: a test-retest. J Environ Econ Policy 1:70-84

Cameron T, Poe G, Ethier R, Schulze W (2002) Alternative nonmarket value- elicitation methods: are revealed and stated preferences the same? J Environ Econ Manag 44(3):391-425

Carson R, Mitchell R (1995) Sequencing and nesting in contingent valuation surveys. J Environ Econ Manag 28(2):155-173

Carson R, Flores N, Meade N (2001) Contingent valuation: controversies and evidence. Environ Resour Econ 19(2):173-210

Castledine A, Moeltner K, Price MK, Stoddard S (2014). Free to choose: promoting Conservation by relaxing outdoor watering restrictions. J Econ Behav Organ 107: 324-343. https://doi.org/10.1016/j.jebo.2014. 02.004

Cooper B, Burton M, Crase L (2011) Urban water restrictions: attitudes and avoidance. Water Resour Res 47, W12527, https://doi.org/10.1029/2010WR010226,2011

Cooper B, Rose J, Crase L (2012) Does anybody like water restrictions? Some observations in Australian urban communities. Aust J Agric Resour Econ 56(1):61-81

Day B, Pinto Prades J (2010) Ordering anomalies in choice experiments. J Environ Econ Manag 59(3):271-285

Fleming C, Bowden M (2009) Web-based surveys as an alternative to traditional mail methods. J Environ Manag 90(1):284-292

Frederickson JR, Waller W (2005) Carrot or stick? Contract frame and use of decision-influencing information in a principal-agent setting. J Account Res 43:709-33

Gordon J, Chapman R, Blamey R (2001) Assessing the options for the Canberra water supply: an application of choice modelling. In: Bennett J, Blamey R (eds) The choice modelling approach to environmental evaluations. Edward Elgar, Cheltenham

Grafton Q, Ward M (2008) Prices versus rationing: Marshallian surplus and mandatory water restrictions. Econ Record. 84, Special Issue 2008, S57-S65

Grafton Q, Kompas T (2007) Pricing sydney water. Aust J Agric Resour Econ 51:227-241

Griffin R, Mjelde J (2000) Valuing water supply reliability. Am J Agric Econ 82(2):414-426

Hensher D, Rose J, Greene W (2005) Applied choice analysis: a primer. Cambridge University Press, Cambridge

Hensher D, Shore N, Train K (2006) Water supply security and willingness to pay to avoid drought restrictions. Econ Rec 256(82):56-66

Hoffman M, Worthington A, Higgs H (2006) Modelling residential water demand with fixed volumetric charging in a large urban municipality: the case of Brisbane, Australia. Aust J Agric Resour Econ 50(3):347-59

Horna J, Smale M, Oppen M (2007) Farmer willingness to pay for seed-related information: rice varieties in Nigeria and Benin. Environ Dev Econ 12:799-825 
Howard K, Salkeld G (2009) Does attribute framing discrete choice experiments influence willingness to pay? Results from a discrete choice experiment in screening for colorectal cancer. Value Health. 12(2):354-363

Howe C, Smith M (1994) The value of water supply reliability in urban water systems. J Environ Econ Manag 26:19-30

Johnston RJ, Rolfe J, Rosenberger R, Brouwer R (eds) (2015) Benefit Transfer of Environmental and Resource Values: A Guide for Researchers and Practitioners. Springer, Netherlands

Kahneman D, Tversky A (1979) Prospect theory: an analysis of decision under risk. Econometrica 27:263-291

Kobayashi M, Moeltner K, Rollins K (2012) Latent thresholds analysis of choice data under value uncertainty. Am J Agric Econ 94(1):189-208

Koss P, Khawaja M (2001) The value of water supply reliability in California: a contingent valuation study. Water Policy 3:165-174

Miller CA (2000) The dynamics of framing environmental values and policy: four models of societal processes. Environ Values 88:211-233

National Water Commissions (NWC) (2007) National Water Commission. National performance report 20052006: major urban water utilities. Melbourne: Water Services Association of Australia

National performance report (2012) 2011-2012: Major urban water utilities. Water Services Association of Australia, Melbourne

Organisation for Economic Co-operation and Development (OECD) (2000) Managing Water for All: An OECD Perspective on Pricing and Financing: Key Messages for Policy Makers; OECD: Paris, France. URL: http://www.oecd.org/env/resources/1934075.pdf (accessed on 14 August 2013)

Ovaskainen V, Kniivila M (2005) Consumer versus citizen preferences in contingent valuation: evidence on the role of question framing. Aust J Agric Resour Econ 49:379-394

Pumphrey RG, Edwards JA, Becker KG (2008) Urban and rural attitudes toward municipal water controls: a study of a semi-arid region with limited water supplies. Ecol Econ 65:1-12

Rabe-Hesketh S, Skrondal A, Pickles A (2004) GLLAMM Manual. C. Berkeley Division of Biostatistics Working Paper Series. Working Paper 160

RealEstate (2017) Real Estate and Investment, URL: www.realestate.com.au/invest. Accessed 1 Sept 2017

Rege M, Telle K (2004) The impact of social approval and framing on cooperation in public good situations. J Public Econ 88:1625-1644

Rigby D, Burton M (2016) Preference stability and choice consistency in discrete choice experiments. Environ Resour Econ 65:441

Rowe R, Schulze W, Breffle W (1996) A test for payment card biases. J Environ Econ Manag 31(2):178-185

Starmer C (2000) Developments in non-expected utility theory: the hunt for a descriptive theory of choice under risk. J Econ Lit 38:332-382

StataCorp. (2013) Stata Statistical Software: Release 11. StataCorp LP, College Station, TX

Syme GJ, Shao Q, Po M, Campbell E (2004) Predicting and understanding home garden water use. Landsc Urban Plan 68:121-128

Tversky A (1996) Contrasting rational and psychological principles in choice. In: Zeckhauser RJ, Keeney RL, Sebenius JK (eds) Wise choices: decisions, games and negotiations. Harvard business School Press, Boston

Tversky A, Kahneman D (1981) The framing of decisions and the psychology of choice. Science 211:453-458

Vossler C, Poe G, Welsh M, Ethier R (2004) Bid design effects in multiple bound discrete choice contingent valuation. Environ Resour Econ 29:401-418

Vossler C, Poe G, Ethier R, Welsh M (2003) Payment certainty in discrete choice contingent valuation responses: results from a field validity test. South Econ J 69(4):216-232

Willis E, Pearce M, Mamerow L, Jorgensen B, Martin J (2013) Perceptions of water pricing during a drought: a case study from South Australia. Water 5:197-223 